\title{
Brief analysis on the status quo and the way of reform of the college practice training
}

\author{
Wei Fu ${ }^{1}$ Pengguang Tang ${ }^{2}$ Qian Li Hao Xie Jian Fang \\ Chongqing Internet of Things Engineering Technology Research Center \\ Key Lab of Network Control Tech.\&Ins., Chongqing University of P\&T, Chongqing, 400065, China \\ E-mail: 61677822@qq.com
}

\begin{abstract}
Along with the high-speed development of the social economy, the enterprises demanding the ability of college students have become increasingly, changes are essentially for the traditional practice teaching mode. This article will analyze the status quo of traditional training teaching mode, and proposed the corresponding countermeasures.
\end{abstract}

Keywords : college; changes; training teaching

\section{INTRODUCTION}

With the development of society, the global science and technology changes every day, high-tech science and technology has penetrated into every aspect of life. The enterprises demanding the ability of college students have become increasingly. However, most of the students in colleges and universities have the status of the "high score but low-energy, or even worse", and that is because of the poor practical ability. If we want this situation to be changed, the research and the changes about the college training mode should be needed. Training courses, in which means after students have finished their theoretical study and skills training, they will have some systematic training by using the basic knowledge and skills in or out of school. This article gave the analysis on how to build all types of colleges teaching training mode and the ideas and methods of reform.

\section{MAIN ISSUES OF PRESENT TRAINING COURSES}

College teaching composed by theoretical teaching and practical teaching, both are equally important. As the development of a new era demand more and more to the modern education, and the colleges are enrolling more students recent years, this makes the practice teaching with theory teaching getting severe challenges. From the current state of practice teaching of colleges we can see there are many problems and shortcomings, this made the traditional practice teaching system has been cannot adapt to the development of higher education, and it cannot suit to educate the highly qualified personnel with a wealth of innovative capacity. ${ }^{[1]}$

According to research found that domestic training course in colleges and universities exists the following mainly issues:

\subsection{The gap between courses and practices}

Practice teaching aims to cultivate high professional skills and practical ability of high-quality compound talents. However the high operational ability majors are mostly based on a lot of theoretical knowledge learning. Only students have structured grasp of scientific theory, can be targeted in the process of practice, and achieve the good practical effect. $\mathrm{Bu}$ the problem that there are too much excess hours on theory teaching and the gap between courses and practice which has existed in the colleges training curriculum design. In recent years, many colleges add a large number of elective courses for students during their practice training in order to adapt to the changes in the job market. This is exacerbate the 
academic burden on student's theoretical courses learning and shorts their time to participate in practical activities. Scientific research shows that according to the theory of teaching that college should have $35 \%$ of the total class hours for the practice teaching, $60 \%$ of the total class hours for the experiment and practice link, and 5\% of the total class hours for the graduation design (paper). But this differentiation is difficult to have result because lack of practice. ${ }^{[2]}$

\subsection{Obsolete teaching mode}

Many colleges and universities are still using the traditional teaching mode without systematic practice teaching materials or information, generally students can get the results only by obey the training steps which is selected and edited by the teachers themselves. These training have done many times by the predecessors; the only different is that students' operation ability and the small error but still they are repeating the same topic. Although such training teaching can improving the operational skills of the students and to deepen the understanding and the consolidation of the theoretical knowledge and consolidation, it still has shortcomings, which is, it difficult to stimulate students' interest in learning and it is impossible to train students diligent in thinking and the independent innovation capability, because of the student is completely follow the content, methods and the steps that all designed by teachers. Because most of the training courses are closed, students can only complete the prescribed training content within the prescribed time, the training room is not open to students in other time. From the perspective of cultivating modern talents, closed traditional practical teaching mode cannot develop the wisdom of the students' abilities and cultivate their innovation consciousness better.

\subsection{Outdated equipment and management mode}

This can be seen in many colleges and universities that the training room construction can't keep up with the demands of the development of teaching. The training teaching has been influenced by the shortage of training funds, training space, and training teaching equipment, and part of the equipments are outdated. From the management mode of training room we can see, outdated management is difficult to guarantee the optimal configuration and resource sharing. A large extent affected has happened on the use efficiency of training rooms because the standardization of the management system is not in place. ${ }^{[3]}$

\section{RESOURCE OF COLLEGE PRACTICE TRAINING REFORM}

\subsection{Adjust the courses arrangement}

It necessary to arranges the courses reasonable for the practice education. Therefore, in the scheduling of the courses, the college should strengthen the culture of innovation ability of the students, and strengthen the practice teaching. For example: explain very practical courses, teachers can lead students directly to the training venue, let the students listen and practice of the content so as to achieve a multiplier effect.

When to carry out the practice teaching, we must overcome teaching idea of "heavy theory, light practice; heavy classroom, light outside the classroom", which according to the actual situation of the school itself, moderately adjust the curriculum to increase the proportion of practice teaching courses, and pay more attention on the implementation of practicing and evaluation of the teaching link monitoring.

\subsection{Reforms the traditional practice teaching mode}

In order to ensure the systemic complete and scientificalness of practical teaching, revising the training syllabus and modify the training materials based the new theory teaching content. Delete outdated, obsolete training content, and merge the repetitive training content, updates to the less representative and typical training. On the basis of retaining the good and verification based training, pay more attention to the students' training methods and training skills. Put the main training time on increasing the type of design, creative, proposition, development and comprehensive training. Those types of training involves the cross and penetration of varies disciplines, which requires students to apply the knowledge according to the training room equipment to designed training program and implementation of the training program by 
themselves, training instructor can directly participate in and give guidance and encouragement through these practical training. Students can improve their comprehensive ability training and culture innovation capability though these training. ${ }^{[4]}$

\section{CONCLUSION}

With the high-speed development of the social economy, there is the higher requirement for Higher Education on how to cultivate the high-quality compound talents. Especially reform the traditional practice teaching mode is very imperative. Reform of the college practice course is not only a simple addition or deletion on one aspect of practical teaching, but also the deepen reform for the whole practice teaching system. It is directly related to both the practice teaching level and quality of the college teaching and also the scientific research level, and, directly affect on cultivation of the creative ability and the high-quality talents. So, under the new situation, it is the responsibility and obligation of every member of our college training teaching team to continue to deepen the reform of practical teaching system, constantly exploring new training teaching mode, continually enhance and improve the management of training teaching.

\section{ACKNOWLEDGMENT}

Popular science series of Internet of things (cstc2012gg-kplB40006), Scientific and technological research project (popular science class) of Chongqing.

Science and technology research projects in 2012 of Chongqing board of education - - The research and application of wireless sensor network based on IPV6 in smart home(KJ120534)

Internet of things the interactive experience on the research and development of library science exhibits and teaching aids (cstc2012gg-kplB40005), scientific and technological research project (popular science class) of Chongqing.

IT popular science bases of Chongqing, key science base construction project of Chongqing.

Construction of automation graduate innovation education bases, key project of graduate education innovation of Chongqing University of P\&T.

Research and practice of the engineering training center construction (1201019), Chongqing higher education teaching reform research project.

\section{REFERENCES}

[1] Tong Shi-hua, "Exploration of the high quality skill type talent training in the higher vocational colleges," Journal of Chongqing College of Electronic Engineering, 2009.07(07),79-81

[2] Tang Yimin, "On the practical teaching of the "five ground," New Technology Innovation Herald, 2009:NO. 29

[3] Zhang Liling, "Strengthen the construction of the training system and practice base," Experimental Technology and Management, 2010.03

[4] Zhao Yalin, "Some suggestions on training curriculum reform," China Educational Technology \& Equipment, 2007(12) 